\title{
Perencanaan Pengembangan Kawasan Pariwisata Pantai Lebih, Desa Lebih, Kabupaten Gianyar
}

Ni Ketut Desi Ariani a, 1, Ida Bagus Suryawan a, 2

1 arianidesi31@gmail.com, 2 idabagussuryawan@unud.ac.id

a Program Studi S1 Destinasi Pariwisata, Fakultas Pariwisata,Universitas Udayana, Jl. Dr. R. Goris, Denpasar, Bali 80232 Indonesia

\section{Abstract}

Lebih beach tourism area is a coastal protection areas in Gianyar Subdistrict. The main problem is the abrasion that occurs along the coastline and damage the naturalness of the beach. Therefore, Gianyar regency government set more coastal tourism area as a priority and certain area, that must be maintained and preserved its existence as a tourism area in Bali. This study aims to determine the planning of tourism area in Lebih Beach to development the priority coast of the tourism area, so it can be worth visiting both in the form of physical and non physical assistance. This research is important to do because the destruction of this coastal environment will determine the sustainability of tourism in Lebih Beach. The research methodology used in this research is mix method, with data source in the form of secondary and primary data. The data collection techniques used in the form are observation, interviews and qualitative documents. After collecting process, the data analyzed descriptively.

The results show that planning for development of the area in Lebih Beach requires several thing, such as direction of the function area, spatial direction, facilities and utilities plan, transportatation plan, indication of priority area program, and activity development plan. Therefore, the participant of every stakeholder is needed for the development planning tourism area to success.

Keywords: Planning, Tourism Area, Lebih Beach

\section{PENDAHULUAN}

Pantai Lebih merupakan sebuah pantai dengan hamparan pasir hitam dengan suasana yang aman dan tenang sehingga cocok untuk wisatawan yang ingin berlibur dan sekedar bersantai. Lokasinya yang berada di Jl. By Pass Ida Bagus Mantra, Desa Lebih, Kecamatan Gianyar, Kabupaten Gianyar terkadang membuatnya dijadikan sebagai rest area bagi wisatawan.

Sebagai wilayah yang telah ditetapkan sebagai salah satu dari enam belas kawasan pariwisata di Bali (Perda Provinsi Bali No. 16 Tahun 2009), Pantai Lebih diharapkan mampu bersaing dengan daya tarik wisata lainnya sebagai pariwisata berkelanjutan dan memberikan berbagai manfaat ke depannya untuk membantu kesejahteraan, baik bagi masyarakat lokal Desa Lebih ataupun bagi kepariwisataan di Bali. Stakeholders yang memiliki peranan penting dalam hal tersebut adalah pemerintah dan masyarakat lokal, di mana pemerintah lebih memahami tentang perencanaan pariwisata secara baik dan benar sedangkan masyarakat berperan dalam hal pengembangan pariwisata dengan pelaksanaan berbagai program kegiatan yang dapat membantu pengembangan di Pantai Lebih. Pemerintah dan masyarakat lokal tentu mengharapkan bahwa pembangunan pariwisata yang dilakukan haruslah mampu memberi dampak positif serta menekan biaya ekonomi, lingkungan, dan sosial.

Kondisi di Pantai Lebih saat ini, dapat dilihat tidak seramai seperti halnya yang ada di Kawasan Kuta, Sanur maupun Jimbaran (Atmojo, 2007). Berbeda dengan kawasan pariwisata pantai lainnya di Bali yang dianggap berhasil, Pantai Lebih justru dianggap kurang berkembang sebagaimana kawasan pariwisata yang menawarkan daya tarik wisata pantai. Hal ini dibuktikan dengan ditetapkannya kawasan pariwisata Pantai Lebih sebagai salah satu kawasan prioritas tertentu yang berada di Kabupaten Gianyar. Penyebab Pantai Lebih menjadi kawasan prioritas karena mengalami abrasi parah yang terjadi di sepanjang pinggiran pantai sehingga menghilangkan kealamian pantai yang seharusnya dimiliki sebuah pantai pada umumnya. Saat ini di bagian tepian Pantai Lebih, banyak terdapat batu-batu untuk menahan gelombang abrasi yang berfungsi agar abrasi tidak menjadi semakin parah. Selain itu sudah mulai terlihat dampak lingkungan yang terjadi di sekitar pesisir Pantai Lebih, yaitu banyaknya sampah yang berserakan dan tidak terawatnya lingkungan sekitar pantai. Adapula fasilitas pariwisata yang sudah tidak layak digunakan seperti toilet, papan tanda yang rusak, dan menara penjaga pantai yang terlihat tidak kokoh. 
Penelitian ini berusaha menganilisis perencanaan kawasan pariwisata di Pantai Lebih untuk membantu pengembangan kawasan pariwisatanya, sehingga hasil yang diperoleh nantinya dapat bermanfaat bagi keberlanjutan keparariwisataan di Pantai Lebih.

\section{KEPUSTAKAAN}

Telaah penelitian sebelumnya yang digunakan kali ini berupa jurnal oleh Nugraha et al. (2015). Jurnal ini memiliki hasil bahwa perencanaan ekowisata di Pantai Sari Ringgung mempertimbangkan fungsi wisata, fungsi konservasi, pendidikan, dan ekonomi. Rancangan dikembangkan melalui pembagian tata ruang wilayah ekowisata hutan mangrove menjadi ruang penerimaan, pelayanan, penyangga seluas, dan ekowisata. Sebagai akses ekowisata dikembangkan tiga jalur sirkulasi yaitu: jalur paving blok, boardwalk, dan kapal. Serta perencanaan kegiatan penataan tanaman pengisi ruang. Persamaan penelitian ini dengan yang sebelumnya terletak pada fokus penelitian, yaitu perencanaan kawasan wisata pantai, sedangkan perbedaannya pada lokasi penelitian.

Telaah penelitian yang kedua berupa jurnal oleh Khomenie dan Umilia (2013). Jurnal ini memiliki hasil bahwa pengembangan kawasan wisata terpadu Kenjeran Surabaya diarahkan pada keterpaduan kawasan yang didukung oleh penyediaan ruang publik, jalur akses internal, program penghijauan, aksesibilitas berupa pengadaan jalur wisata internal dan eksternal, jalur pejalan kaki, penyediaan sarana dan prasarana transportasi, pemusatan kegiatan perdagangan, meningkakatkan acara rakyat, zona utama adalah pantai, sosialisasi dan pelatihan, perpustakaan umum dan penciptaan identitas kawasan. Persamaan penelitian ini dengan yang sebelumnya terletak pada fokus penelitian, yaitu arahan kawasan wisata pantai, sedangkan perbedaannya pada lokasi penelitian.

Tinjauan konsep yang digunakan dalam penelitian ini adalah konsep perencanaan pariwsata, konsep kawasan pariwisata dan knsep pengembangan pariwisata

\section{METODE PENELITIAN}

Pantai Lebih yang dipilih sebagai lokasi penelitian terletak di Jl. By Pass Ida Bagus Mantra, Desa Lebih, Kecamatan Gianyar, Kabupaten Gianyar. Adapun jenis data yang dipergunakan adalah data kualitatif, yaitu gambaran umum lokasi penelitian dan deskripsi tiap perencanaan kawasan pariwisata di Pantai Lebih. Data kuantitatif berupa data pendapatan perkapita masyarakat pada sektor yang berkaitan dengan pariwisata dan data luas sempadan pantai di Pantai Lebih.

Sumber data yang dipergunakan adalah data sekunder, yaitu dokumen profil Desa Lebih selaku pengelola Pantai Lebih, serta jurnal atau literatur lainnya yang terkait pengembangan pariwisata Pantai Lebih. Data primer berupa data langsung dari penelitian di lapangan mengenai perencanaan kawasan pariwisata di Pantai Lebih yang didapat melalui observasi dan wawancara.

Teknik pengumpulan data yang dipergunakan dalam penelitian ini dilakukan dengan metode observasi, yaitu pengamatan langsung ke daya tarik wisata Pantai Lebih untuk mengetahui aktivitas masyarakat, mengamati kondisi Pantai Lebih, dan mengetahui gambaran dari lokasi tempat penelitian. Wawancara dengan karyawan kantor perbekel Desa Lebih dan masyarakat lokal Desa Lebih untuk mengetahui kondisi eksisting pariwisata Pantai Lebih saat ini serta pendapat masyarakat tentang berbagai hal yang terjadi di kawasan pariwisata di Pantai Lebih.

Analisis data yang dipergunakan adalah deskriptif kualitatif, yaitu menekankan pada penggalian informasi terkait, di mana hasilnya digambarkan dalam bentuk kata atau kalimat yang kemudian penyusunannya dilakukan secara teratur dan akurat sesuai fakta yang ada di lapangan sehingga hasil yang didapatkan terkait dengan perencanaan kawasan pariwisata di Pantai Lebih dapat dijelaskan dengan baik.

\section{HASIL DAN PEMBAHASAN \\ 4.1 Arahan Fungsi Kawasan}

Arahan rencana pengembangan kawasan prioritas Pantai Lebih dibagi menjadi dua, yaitu : 
a. Arahan Fungsi Kawasan Pantai Lebih difokuskan pada empat aspek, yaitu :

1. Kawasan pemandangan alam berupa pantai sebagai potensi wisata alam

2. Pengembangan kuliner khas, yaitu makanan laut (seafood)

3. Penataan fasilitas penunjang wisata secara umum

4. Pengembangan atraksi wisata pesisir dengan menghubungkan berbagai aspek, seperti binaan terhadap wisata pesisir kemudian terhadap budaya serta aspek terhadap lingkungan alami.

b. Arahan Kebijakan Pengembangan Kawasan Pantai Lebih difokuskan pada enam aspek, yaitu :

1. Mempertahankan keberadaan areal pantai sebagaimana mestinya sebagai aset utama wisata alam

2. Meningkatakan hasil produksi lokal, utamanya ikan sebagai penunjang kuliner khas laut sebagai lapangan pekerjaan masyarakat setempat

3. Membatasi dan melarang segala macam kegiatan untuk membangun fasilitas pariwisata di kawasan yang memiliki fungsi lindung

4. Membangun fasilitas penunjang pariwisata berupa akomodasi pariwisata bagi wisatawan sesuai dengan kebutuhan

5. Memberikan pemahaman kepada masyarakat mengenai ekosistem pesisir sehingga nantinya memberi kesadaran tentang bagaimana cara masyarakat harusnya bersikap dalam berupaya melestarikan wilayah pesisir agar lebih berwawasan terhadap lingkungan serta menyesuaikan dengan prinsip-prinsip untuk pembangunan yang berkelanjutan.

6. Pengembangan berupa suatu sistem manajemen atau pengelolaan pesisir untuk wisata bahari dimana didasarkan pada pengembangan yang berkelanjutan, lingkungan alam, meningkatkan kesejahteraan bagi masyarakat serta berdasar karakter dan budaya bahari.

\subsection{Arahan Tata Ruang}

Mengacu pada Perda No.16 Tahun 2009 tentang Rencana Tata Ruang Wilayah Provinsi Bali tahun 2009-2029, perencanaan arahan tata ruang Pantai Lebih dijabarkan sebagai berikut:

a. Menata kembali kawasan pariwisata berupa kawasan sempadan pantai yang memiliki masalah abrasi

b. Mengembangakan kawasan pariwisata berbasis daya tarik wisata alam

c. Pelaksanaan pembangunan di kawasan pariwisata Pantai Lebih untuk meningkatakan kesejahteraan masyarakat

d. Pengelolaan sebuah kawasan prioritas sempadan pantai

e. Keterpaduan rencana pengembangan kawasan Pantai Lebih dengan kawasan pariwisata lainnya

f. Pengembangan dan pengendalian terhadap perkembangan secara fisik dan membatasi izin terhadap pengembangan baru di kawasan terbangun yang tidak sesuai kebutuhan

g. Peningkatan untuk kualitas dan kuantitas pelayanan pada sarana dan prasarana pariwisata pada sebuah kawasan prioritas

h. Membangun fasilitas pariwisata yang sesuai dengan tingkat kebutuhan untuk menunjang jalannya kepariwisataan

\subsection{Rencana Fasilitas dan Utilitas}

Fasilitas diperlukan sebagai pendukung dalam kegiatan pariwisata, terlebih pada suatu kawasan pariwisata. Oleh karena itu diperlukan perencanaan berbagai fasilitas yang ada di Pantai Lebih untuk menunjang berjalaanya kepariwisataan. Hal tersebut dijelaskan pada Tabel 4.1.

Tabel 4.1

\section{Rencana Fasilitas dan Utilitas Pantai Lebih}

\begin{tabular}{|l|l|l|}
\hline Jenis fasilitas & \multicolumn{1}{|c|}{ Utilitas } & Keterangan \\
\hline Kesehatan : & Penanganan & Ditempatka \\
- Puskesmas & kesehatan bagi & n ditempat \\
- Tempat & wisatawan yang & yang tenang \\
praktek & mengalami sakit dan & dan \\
- Apotek/toko & luka saat melakukan & diusahakan \\
obat & aktivitas wisata di & mempunyai \\
& Pantai Lebih sebagai & radius yang \\
& upaya pertolongan & merata \\
\hline
\end{tabular}




\begin{tabular}{|c|c|c|}
\hline & pertama & \\
\hline $\begin{array}{l}\text { Akomodasi : } \\
\text { - Homestay } \\
\text { - Penginapan } \\
\text { dan } \\
\text { hotel } \\
\text { - Restoran } \\
\text { - Supermarket }\end{array}$ & $\begin{array}{lr}\text { Sarana } & \text { tempat } \\
\text { menginap } & \\
\text { sementara, tempat } \\
\text { makan dan tempat } \\
\text { belanja kebutuhan } \\
\text { sehari-hari } r \text { bagi } \\
\text { wisatawan selama } \\
\text { berada di } & \text { objek } \\
\text { wisata } & \end{array}$ & $\begin{array}{l}\text { Lokasi } \\
\text { tersebar } \\
\text { dan } \\
\text { disesuaikan } \\
\text { dengan } \\
\text { tingkat } \\
\text { kebutuhan } \\
\text { serta sesuai } \\
\text { tata ruang } \\
\text { kawasan }\end{array}$ \\
\hline $\begin{array}{l}\text { Sarana } \\
\text { Pendukung } \\
\text { - Tempat } \\
\text { parkir } \\
\text { - Loket masuk } \\
\text { - Toilet } \\
\text { - Pos } \\
\text { keamanan } \\
\text { - Menara } \\
\text { Penjaga } \\
\text { Pantai } \\
\text { - Tempat } \\
\text { ibadah }\end{array}$ & \begin{tabular}{lr} 
Untuk mendukung \\
kegiatan & wisata \\
\multicolumn{2}{l}{ yang dilakukan oleh } \\
wisatawan & ketika \\
berada di & objek \\
wisata &
\end{tabular} & $\begin{array}{l}\text { Lokasi } \\
\text { berada di } \\
\text { sekitar } \\
\text { pantai dan } \\
\text { disesuaikan } \\
\text { dengan } \\
\text { tingkat } \\
\text { kebutuhan }\end{array}$ \\
\hline $\begin{array}{l}\text { Perdagangan : } \\
\text { - Pertokoan } \\
\text { kecil berupa } \\
\text { kerajinan } \\
\text { tangan khas } \\
\text { masyarakat } \\
\text { lokal } \\
\text { - Pasar } \\
\text { tradisional } \\
\text { penunjang } \\
\text { objek wisata }\end{array}$ & $\begin{array}{lr}\text { Perdagangan } & \text { akan } \\
\text { membantu } & \\
\text { wisatawan } & \\
\text { memenuhi } & \\
\text { keinginan } & \text { untuk } \\
\text { melakukan } & \text { wisata } \\
\text { belanja } & \\
& \end{array}$ & $\begin{array}{l}\text { Lokasi } \\
\text { berada di } \\
\text { sekitar } \\
\text { pantai dan } \\
\text { disesuaikan } \\
\text { dengan } \\
\text { tingkat } \\
\text { kebutuhan }\end{array}$ \\
\hline
\end{tabular}

\subsection{Rencana Transportasi}

Rencana untuk sarana dan prasarana transportasi memiliki peran yang penting, dimana hal tersebut adalah untuk memperlancar aksesibilitas wisatawan ke daerah tujuan. Seperti pada umumnya, prasarana jalan pada suatu wilayah, dituntut untuk dapat memberi kemudahan, baik bagi wisatawan ataupun masyarakat.

Pantai Lebih sendiri memiliki aksesibilitas yang sangat baik, terutama jalan menuju ke desa ataupun pantainya, hal ini dikarenakan lokasi Pantai Lebih berada di tengah Jl. By Pass yang memiliki jalan aspal besar dan lancar. Wisatawan tidak perlu merasa takut terkena macet ketika menuju Pantai Lebih. Selain itu, Pantai Lebih memiliki tempat parkir yang cukup luas jika hanya sebagai rest area, sehingga bisa menampung sepeda motor, mobil, dan mini bus di dalam areal sekitar pantai dan bus pariwisata besar di luar areal pantai.

Dalam rangka meningkatkan sistem perkerasan jalan dimasa datang, pemerintah haruslah mengutamakan jalan-jalan menuju ke pusat-pusat pelayanan yang dianggap penting dan dibutuhkan baik oleh wisaawan maupun masyarakat, serta menghubungkan daerah kawasan perencanaan (Pantai Lebih) dengan daerah produksi (Desa Lebih).

Walaupun sudah memiliki akses jalan yang baik, pengembangan sistem jaringan pada transportasi wilayah dapat dilakukan dengan cara mendalami karakteristik yang dimiliki kawasan dan bentuk fisik dari kawasan serta kondisi geografi yang ada, sehingga dapat dikembangkan sistem jaringan yang lebih baik, terutama untuk sistem transportasi di darat. Transportasi darat ditujukan utamanya melalui pengembangan pada jaringan sarana dan prasarana jalan untuk masyarakat yang memiliki usaha pariwisata yang jauh dengan lokasi objek wisata dan tempat tinggal mereka, kemudian arahan transportasi darat bagi wisatawan untuk memasuki daerah objek wisata. Dimana karakteristik lalu lintas kendaraan melalui akses jalan tersebut adalah, dimana pada bagian persimpangan dapat dikendalikan berdasarkan kebutuhan dan untuk percepatannya berada di kecepatan sedang.

\subsection{Indikasi Program Kawasan Prioritas}

Berikut dijelaskan mengenai indikasi program kawasan prioritas yang dapat dilakukan di Pantai Lebih dalam Tabel 4.2 :

Tabel 4.2

Indikasi Program Kawasan Prioritas Pantai Lebih

\begin{tabular}{|c|c|}
\hline Nama Program & Tujuan \& Sasaran \\
\hline $\begin{array}{l}\text { 1. Penataan kawasan } \\
\text { melalui penyusunan } \\
\text { Rencana Teknik } \\
\text { Kawasan Pariwisata } \\
\text { Pantai Lebih } \\
\text { 2. Penataan } \\
\text { Pembangunan } \\
\text { melalui penyusunan }\end{array}$ & $\begin{array}{l}\text { 1. Menarik kunjungan } \\
\text { wisata } \\
\text { 2. Memenuhi } \\
\text { kebutuhan fasilitas } \\
\text { kepariwisataan } \\
\text { bagi masa datang, } \\
\text { sesuai dengan } \\
\text { tingkat kunjungan }\end{array}$ \\
\hline
\end{tabular}




\begin{tabular}{|c|c|}
\hline $\begin{array}{l}\text { RTBL (Rencana Tata } \\
\text { Bangunan dan } \\
\text { Lingkungan) di } \\
\text { Pantai Lebih } \\
\text { 3. Penyusunan } \\
\text { Pedoman Prosedur } \\
\text { Pelaksanaan } \\
\text { Pembangunan } \\
\text { 4. Penyiapan } \\
\text { akomodasi wisata di } \\
\text { Kawasan Wisata } \\
\text { Lebih } \\
\text { 5. Peningkatan sarana } \\
\text { dan prasarana untuk } \\
\text { menunjang } \\
\text { wisatawan, promosi } \\
\text { wisata dan penataan } \\
\text { obyek wisata } \\
\text { 6. Prumusan berbagai } \\
\text { peraturan daerah }\end{array}$ & $\begin{array}{ll}\text { wisatawan } \\
\text { 3. } & \begin{array}{l}\text { Meningkatkan } \\
\text { jumlah wisatawan } \\
\text { dan lama tinggal } \\
\text { 4. }\end{array} \\
\text { Pengembangan } \\
\text { dan pengendalian } \\
\text { perkembangan } \\
\text { fisik atau } \\
\text { membatasi izin } \\
\text { pengembangan } \\
\text { baru kawasan } \\
\text { terbangun yang } \\
\text { tidak sesuai } \\
\text { kebutuhan }\end{array}$ \\
\hline
\end{tabular}

Sumber : Hasil Penelitian Lapangan (2017)

Instansi terkait yang dapat dilibatkan adalah Bappeda Kabupaten Gianyar, Dinas Pariwisata Kabupaten Gianyar dan Dinas PU Kabupaten Gianyar.

Sumber dana yang bisa diajukan dapat melalui APBN, APBD Provinsi, APBD Kabupaten, dan Swasta.

\subsection{Rencana Pengembangan Kegiatan}

Setelah mengetahui berbagai perencaanaan kawasan prioritas diatas, maka diperlukan rencana pengembangan kegiatan yang akan dilakasankan, yaitu :

a. Perencanaan di bagian fisik yang berkaitan dengan pemanfaatan tata ruang :

1) Pemanfaatan zona kawasan berdasarkan penyebarannya

2) Pemanfaatan sarana dan prasarana penujang pariwisata

3) Pengembangan jaringan transportasi dan aksesibilitas

b. Pengembangan program pembangunan kepariwisataan

1) Penataan kawasan melalui penyusunan Rencana Teknik Kawasan Pariwisata Pantai Lebih

2) Penataan Pembangunan melalui penyusunan RTBL (Rencana Tata
Bangunan dan Lingkungan) di Pantai Lebih

3) Penyusunan Pedoman Prosedur Pelaksanaan Pembangunan

4) Penyiapan bebagai fasilitas akomodasi wisata di Kawasan Wisata Lebih

5) Peningkatan sarana \& prasarana untuk menunjang wisatawan, promosi wisata dan penataan obyek wisata

c. Pembentukan sistem kelembagaan di daerah

1) Pembentukan badan perencanaan pariwisata

2) Pembentukan badan promosi pariwisata

d. Pencarian sumber pendanaan kegiatan program

1) Pengidentifikasian sumber-sumber PAD (Pendapatan Asli Daerah) sektor pariwisata

2) Pengalokasian dana untuk membiayai program kepariwisataan

\section{PENUTUP}

\subsection{Simpulan}

Pantai Lebih termasuk dalam kategori kawasan lindung sempadan pantai. Selain sebagai kawasan lindung sempadan pantai, Pantai Lebih termasuk dalam pengembangan wilayah prioritas dan kawasan tertentu.

Oleh karena itu diperlukan arahan pengembangan kawasan prioritas bagi perencanaan Pantai Lebih agar berbagai permasalahan yang timbul dapat ditangani dan tidak mengancam keselamatan kegiatan pariwisata yang ada di Pantai Lebih. Berikut adalah rencana arahan pengembangan kawasan prioritas Pantai Lebih yang dibagi ke dalam beberapa kelompok rencana, yaitu :
a. Arahan Fungsi Kawasan
b. Arahan Tata Ruang
c. Renacan Fasilitas dan Utilitas
d. Rencana Transportasi
e. Indikasi Program Kawasan Prioritas
f. Rencana Pengembangan Kegiatan

\subsection{Saran}

a. Kepada pemerintah terkait diharapkan dapat membantu perencanaan pengembangan kawasan pariwisata Pantai Lebih baik berupa bantuan fisik maupun non fisik sehingga sebuah kawasan prioritas seperti Pantai Lebih ini dapat 
menjadi kawasan pariwisata yang layak untuk dikunjungi, selain itu, pemerintah seharusnya lebih tanggap terhadap kawasan-kawasan yang memiliki proritas tertentu seperti Pantai Lebih ini.

b. Untuk masyarakat lokal diharapkan terus berpartisipasi di setiap kegiatan pariwisata di Pantai Lebih yang diselenggrakan lembaga masyarakat sebagai keterlibatan aktif di kawasan pariwisata dan kerjasama lembagalembaga terkait untuk pengelolaan Pantai Lebih.

\section{DAFTAR PUSTAKA}

Anonim. 2009. Perda Provinsi Bali No.16 Tahun 2009 tentang Rencana Tata Ruang Wilayah Provinsi Bali Tahun 2009-2029.

Anonim. 2007. Undang - Undang No. 26 Tahun 2007 Tentang Penataan Ruang

Anonim. 2009. Perda Provinsi Bali No. 16 Tahun 2009

Atmojo, WT. 2007. Pariwisata di Gianyar Bali dari Wisata Budaya sampai Wisata Wana. Fakultas Bahasa dan Seni Universitas Negeri Medan

Kanom. 2015. Strategi pengembangan kuta lombok sebagai destinasi pariwisata berkelanjutan. JUMPA Vol 1 No.2

Khomenie, A., Umilia E. 2013. Arahan Pengembangan Kawasan Wisata Terpadu Kenjeran Surabaya. Jurnal Teknik Pomits. Vol 2 No. 1. h C-87 - C-91

Mill, R.C., 2000. Tourism The International Business, Edisi Bahasa Indonesia. Jakarta: Penerbit PT Raja Grafindo Persada.

Nugraha, N., Banuwa I.S., Widagdo S. 2015. Perencanaan Lanskap Ekowisata Hutan Mangrove di Pantai Sari Ringgung Desa Sidodadi Kecamatan Padang Cermin Kabupaten Pesawaran. Jurnal Sylva Lestari. Vol 3 No. 2. h 53-66

Paturusi, Syamsul Alam. 2008. Perencanaan Kawasan Pariwisata. Denpasar : Press UNUD

Pitana, I G. dan Gayatri P.G. 2005. Sosiologi Pariwisata. Yogyakarta : CV Andi Offset

Wardana. 2017. Potensi dan Strategi Pengembangan Pariwisata di Kabupaten Pesisir Barat. Bandar Lampung. Universitas Lampung

Sumber lain :

www.gianyarkab.go.id diakses 19 Mei 2017 pukul 05.30 p.m 